\title{
Gastric cancer with breast metastasis: Clinical features and prognostic factors
}

\author{
YUE MA ${ }^{1 *}$, WENWEN LIU ${ }^{2 *}$, JUNJIAN LI ${ }^{3}$, YINGCHUN XU ${ }^{1}$ and HONGXIA WANG ${ }^{3}$ \\ Departments of ${ }^{1}$ Oncology and ${ }^{2}$ Geratology, Renji Hospital, School of Medicine, Shanghai Jiaotong University, \\ Shanghai 200127; ${ }^{3}$ Department of Oncology, General Hospital, School of Medicine, \\ Shanghai Jiaotong University, Shanghai 200080, P.R. China
}

Received July 29, 2017; Accepted February 22, 2018

DOI: $10.3892 / \mathrm{ol} .2018 .9383$

\begin{abstract}
Metastatic spread of gastric carcinoma to the breast is rare. In previous decades, reports on this subject were minimal and primarily limited to case reports. At present, little is known on the clinicopathological features and prognosis of this condition, and breast metastasis remains a challenging clinical problem. A total of 54 cases of breast metastasis from gastric cancer were collected from databases between January 1960 and December 2016. The present study included 3 cases of gastric cancer with breast metastasis from Renji hospital and 51 additional cases from previous studies. The clinicopathological features of patients, including epidemiology, symptoms, macroscopic presentation, pathological diagnosis, imaging, treatment and overall survival time, were analyzed. The median survival time was 8.6 months. All but one of the patients were female, and the median age at diagnosis of breast metastasis was 43 years old (age range, 22-72 years). A majority of patients presented with Borrmann class III disease, signet ring cell carcinoma, T4 tumor types, lymph node involvement, initial stage IV gastric cancer, primary lesions in the gastric antrum, left breast metastasis and palpable breast nodules. The median interval between the primary gastric carcinoma diagnosis and presentation of breast metastasis was 1.25 months (range, $0-72$ months). The expression of the estrogen receptor, progesterone receptor, human epidermal growth factor receptor- 2 and gross cystic
\end{abstract}

Correspondence to: Dr Yingchun Xu, Department of Oncology, Renji Hospital, School of Medicine, Shanghai Jiaotong University, 160 Pujian Road, Pudong, Shanghai 200127, P.R. China

E-mail: xiaoxu2384@163.com

Dr Hongxia Wang, Department of Oncology, General Hospital, School of Medicine, Shanghai Jiaotong University, 650 New Songjiang Road, Songjiang, Shanghai 200080, P.R. China

E-mail:whx365@126.com

${ }^{*}$ Contributed equally

Key words: gastric cancer, breast metastasis, metastatic tumor, outcome, overall survival disease fluid protein-15 was negative in the patients with breast metastases. In univariate analysis, age, gastric tumor size, gastric lymph node involvement and breast metastasis histology were significantly associated with overall survival (OS) time ( $\mathrm{P}=0.001,0.039,0.034$ and $<0.001$, respectively). Therapeutically, gastric surgery and chemotherapy were not associated with OS ( $\mathrm{P}=0.959$ and 0.290 , respectively). In further multivariate analysis, the time between occurrence $(\mathrm{P}=0.017)$, age $(\mathrm{P}=0.009)$, histology $(\mathrm{P}=0.045)$ and breast metastasis localization $(\mathrm{P}=0.043)$ were independent indicators of OS time. Although breast metastasis from gastric cancer is rare, physicians should be vigilant when patients with a history of gastric cancer present with newly developed mammary symptoms and signs.

\section{Introduction}

Primary breast cancer is a common malignancy in females and remains the leading cause of cancer-associated mortalities among females globally despite advances in screening, diagnosis, and treatment (1); however, breast metastasis from an extramammary neoplasm is uncommon, constituting only $0.5-2.0 \%$ of all mammary malignancies $(1,2)$. The most common origins of breast metastasis are malignant melanoma, lymphoma, lung cancer, ovarian carcinoma and soft tissue sarcoma, followed by gastrointestinal and genitourinary tumor types (3-6).

Gastric carcinoma is the third most common carcinoma in Korean females, followed by breast and thyroid carcinoma in the past decade (7). There were estimated to have been $\sim 1,000,000$ new cases of gastric cancer in 2012, making it the fifth most common malignancy and the third leading cause of cancer mortality for females and males globally (8). Common sites of distant metastasis of gastric cancer include the peritoneum, liver, lymph nodes, and lungs. The breast is a rare site of metastasis in gastric cancer (9). Metastatic tumors frequently contain similar immunohistochemical characteristics to the primary tumors, and it is important to determine whether the breast lesions are primary or metastatic from gastric cancer, in order to determine the surgical intervention required (10-17). Owing to the low frequency of the disease, only sporadic cases or a small series of cases of patients with breast metastases from gastric cancer have been published so far (18). The majority of 
the previous studies focused on clinical presentation and immunohistochemical characteristics rather than specific treatment and prognostic variables $(2,19-22)$; therefore, little is known about the biological behavior, clinicopathological features, optimal treatment and prognosis of this condition. Thus, clinical researchers may face numerous challenges when conducting a prospective randomized case-control clinical study to compare the treatment programs and outcomes in this rare clinical entity. The previous study demonstrated that treatment strategies, including intensive multi-agent chemotherapy, surgery, radiation and targeted therapy, however, the treatment strategies to achieve complete remission or partial remission remain controversial (23). The present study included 3 cases of gastric cancer with breast metastasis from Renji Hospital (Shanghai, China) and 51 additional cases from previous studies (9,10,12,13,23-66). The primary origin, clinicopathological features, treatments and survival data were systematically collected and analyzed in order to evaluate whether these factors may serve potential roles as prognostic and predictive biomarkers of patients with gastric cancer and breast metastasis.

\section{Materials and methods}

Data collection. The inclusion criteria included: A pathological diagnosis of gastric cancer with breast metastasis; and willing to sign informed consent. The exclusion criteria included: No definite pathology; and unwilling to sign informed consent. To obtain data on studies detailing patients with gastric cancer with breast metastasis, studies in databases from between January 1960 and December 2016, including PubMed, MEDLINE, Embase, Google Scholar, Wanfang Database, China Science, Technology Periodical Database and China Journal Net, were assessed using the keywords 'gastric or stomach', 'tumor or cancer or carcinoma', 'breast or mammary' and 'metastasis'. All titles, abstracts and associated citations were scanned and reviewed. Relevant references from which these data were obtained have been included $(9,10,12,13,23-66)$. A total of three patients diagnosed with gastric cancer and breast metastases in the Renji Hospital, from January 2003 to December 2017 were retrospectively reviewed. All patients were female with a median age of $49.00 \pm 1.73$ years old (age range, $48-51$ years). Of these patients, two of them were diagnosed with breast lesions 3 years following gastric cancer surgery, and one was concurrently diagnosed with gastric cancer and breast metastasis. All of the patients received chemotherapy, and one of them received surgery for breast lesions. Ethical approval was obtained from Human Clinical and Research Ethics Committees of Renji Hospital Affiliated to Shanghai Jiaotong University and written informed consent was obtained from the patients prior to the study. The following data were collected: Epidemiological, symptomatological, macroscopic presentation, pathological diagnosis, imaging performance, time between primary gastric cancer diagnosis and breast metastasis detection, treatment and prognosis.

Hematoxylin-eosin $(H \& E)$ and immunohistochemical staining. Tissue samples derived from resected and core needle biopsy specimens were fixed in $10 \%$ formalin at room temperature for $24 \mathrm{~h}$, paraffin embedded and subjected to histological or immunohistochemical analysis. Sections $(4 \mu \mathrm{m})$ were heated at $58^{\circ} \mathrm{C}$ for $2 \mathrm{~h}$ and then deparaffinized in xylene and hydrated with a series of graded alcohols, including anhydrous ethanol for $5 \mathrm{~min}, 95 \%$ ethanol for $2 \mathrm{~min}, 90 \%$ ethanol for $2 \mathrm{~min}$, $80 \%$ ethanol for $2 \mathrm{~min}$ and $70 \%$ ethanol for $2 \mathrm{~min}$. H\&E staining was used for histological analysis. Antigen recovery was performed by heating and immersing the slides in citrate buffer (0.01 M, pH 6.0; cat. no. P0020; Noble-Ryder Technology Co., Ltd., Beijing, China) in a microwave oven $\left(121^{\circ} \mathrm{C}\right)$ for $10 \mathrm{~min}$ twice. Endogenous peroxidase activity was blocked using $3 \%$ hydrogen peroxide for $30 \mathrm{~min}$ at $20^{\circ} \mathrm{C}$, and the sections were incubated with anti-cytokeratin 7 (CK7; 1:50; cat. no. OV-TL12/30; Dako; Agilent Technologies, Inc., Santa Clara, CA, USA), CK20 (1:80; cat. no. M7019; Dako; Agilent Technologies, Inc.), mucin 1 (1:50; cat. no. MRQ-17; AmyJet Scientific, Inc., Wuhan, China), Ki-67 (1:100; cat. no. MIB-1; Dako; Agilent Technologies, Inc.), gross cystic disease fluid protein-15 (GCDFP-15; 1:50; cat. no. 23A3; Dako; Agilent Technologies, Inc.), mammaglobin (1:100; cat. no. TA327698, OriGene Technologies, Inc., Beijing, China), villin (1:100; cat. no. 1D2C3) and carcinoembryonic antigen (CEA; 1:100; cat. no. II-7; both Dako; Agilent Technologies, Inc.), respectively, at $4^{\circ} \mathrm{C}$ overnight. Subsequently, the sections were washed with PBS three times for 2 min and incubated with a biotinylated anti-mouse (cat. no. D0486) /anti-rabbit secondary antibody (cat. no. D0487; 1:500; Dako; Agilent Technologies, Inc.) at $37^{\circ} \mathrm{C}$ for $15 \mathrm{~min}$. The signal was detected with a 3,3'diaminobenzidine kit (Dako; Agilent Technologies, Inc.). Finally, the sections were counterstained with hematoxylin solution at room temperature for $5 \mathrm{~min}$. The positive immunostaining cells were counted and imaged under a light microscope (Olympus BX43; Olympus Corporation, Tokyo, Japan) with a magnification of x100 and x400. The negative control was conducted by replacing the primary antibody with $0.1 \%$ bovine serum albumin (cat. no. BAH62-0100; AmyJet Scientific, Inc.)/PBS.

Statistical analysis. All statistical analyses were performed using SPSS version 17.0 (SPSS, Inc., Chicago, IL, USA) and numeric parameters presented as the mean \pm standard deviation. Survival data were defined as the time from breast metastasis until the date of mortality or last follow-up, and median overall survival (OS) time was estimated using the Kaplan-Meier method and the log-rank test was used for comparison of outcomes. Multivariate analysis was performed to confirm independent predictors by using a step-forward logistic regression approach for the Cox proportional hazards model, and $\mathrm{P}<0.05$ was considered to indicate a statistically significant difference.

\section{Results}

Clinicopathological characteristics of patients with primary gastric cancer. A total of 54 cases that were enrolled in the present study, 51 of which were from previous studies $(9,10,12,13,23-66)$. The primary gastric cancer characteristics are summarized in Table I. All but one of the patients were female. A total of 30 cases were available with Borrmann classification (67) data, including Borrmann I in 3 cases (5.6\%), II in 2 cases (3.7\%), III in 17 cases (31.5\%) and IV in 8 cases $(14.8 \%)$. For the primary gastric carcinoma location, 33 cases were available for analysis. Of these cases, 9 cases $(16.7 \%)$ had lesions in the gastric corpus, $19(35.2 \%)$ in the gastric antrum, 
Table I. Clinicopathological information of patients with primary gastric tumor types.

\begin{tabular}{llll}
\hline Variables & Patients, $\mathrm{n}$ & Log rank-value & Univariate P-value
\end{tabular}

Sex

Female

Male

53

1

2

17

III

IV

Unknown

8

24

Tumor position

Gastric corpus

Gastric antrum

Gastric fundus

Linitis plastica

Unknown

Tumor size

T1

$\mathrm{T} 2$

T3

T4

Unknown

Lymph node involvement

Positive

Negative

Unknown

Coexisting metastasis in other organs

Positive

Negative

Unknown

Initial stage

I

II

III

IV

Unknown

Histology

$\mathrm{AC}$

SIG

PDA

MAC

Unknown
98.1

1.9

2.203

0.138

5.6

3.7

31.5

14.8

44.4

3.067

0.381

16.7

35.2

1.9

7.4

38.9

7.746

0.052

5.6

5.6

7.4

25.9

55.6

8.342

0.039

35.2

5.6

59.3

4.474

0.034

44.4

37.0

18.5

0.090

0.764

3.7

7.4

11.1

44.4

33.3

4.231

0.238

1.9

68.5

22.2

5.6

1.9

0.605

0.895

PDA, poorly differentiated adenocarcinoma; SIG, signet ring cell carcinoma; MAC, mucinous adenocarcinoma; AC, adenocarcinoma; T, tumor.

4 cases $(7.4 \%)$ in the linitis plastica and 1 case $(1.9 \%)$ in the gastric fundus (Table I).

Tumor-Node-Metastasis staging was performed according to the 2003 American Joint Committee on Cancer staging system (68). Information on patient $\mathrm{T}$ staging were provided in the previous studies that were analyzed. Not all data provided was complete, hence not all patients had tumor staging data. Tumor size was available in only 24 cases; of these, 14 cases 
A

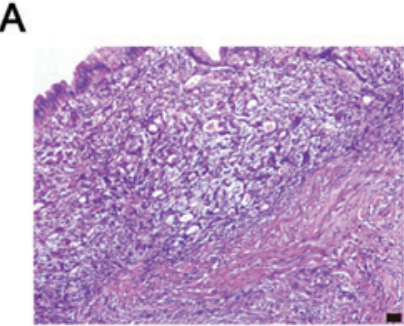

B

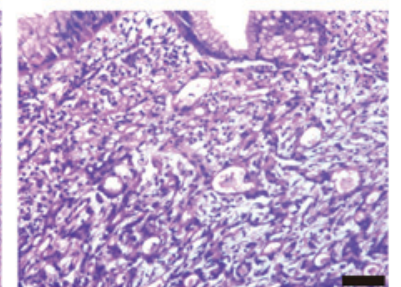

C

D

E

$\mathrm{F}$
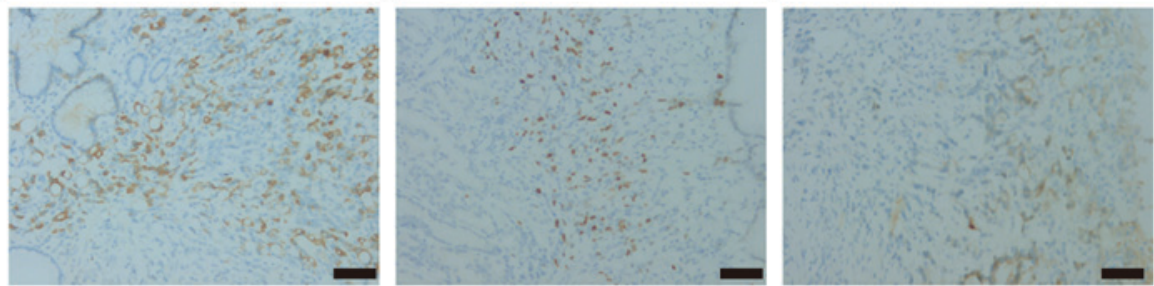

G

$\mathrm{H}$
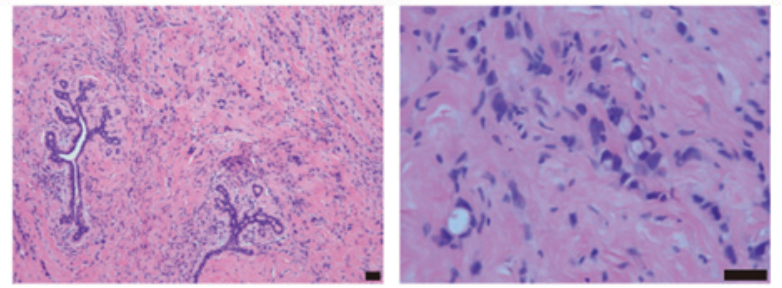

I

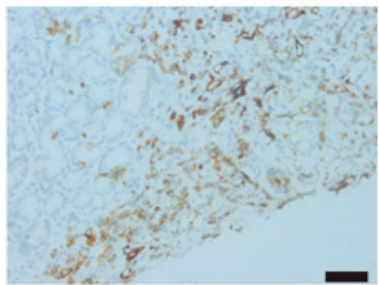

$\mathbf{J}$

$\mathrm{K}$
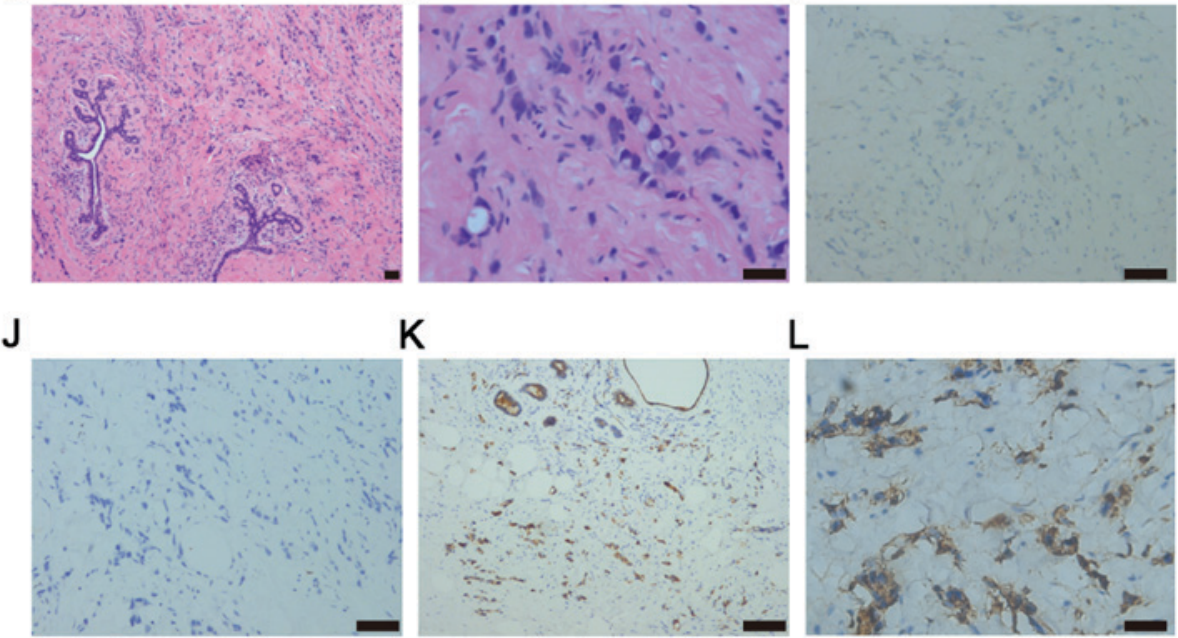

L
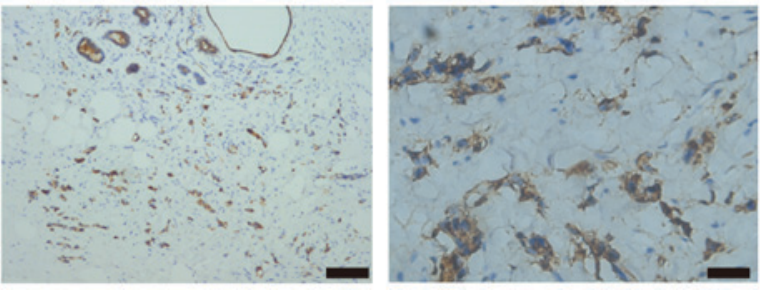

Figure 1. H\&E staining and immunohistochemical analysis of one gastric cancer and breast metastasis case that was positive for CK7, CK20 and MUC-1 and $30 \%$ positive for Ki-67. Scale bar, $100 \mu \mathrm{m}$. (A) H\&E staining of a low-power field (x10) of gastric cancer tissue. (B) H\&E staining of a high-power field of gastric cancer tissue. (C) Gastric cancer tissue positive for CK7. (D) Gastric cancer tissue positive for CK20. (E) Gastric cancer tissue that is positive for Ki-67. (F) Gastric cancer tissue positive for MUC-1. (G) H\&E staining of a low-power field of metastatic breast cancer tissue. (H) H\&E staining of a high-power field of metastatic breast cancer tissue. (I) Metastatic breast cancer tissue negative for gross cystic disease fluid protein-15. (J) Metastatic breast cancer tissue that is negative for mammaglobin. (K) Metastatic breast cancer tissue positive for villin. (L) Metastatic breast cancer tissue positive for carcinoembryonic antigen. H\&E, hematoxylin and eosin; CK7, cytokeratin 7; CK20, cytokeratin 20; MUC-1, mucin 1, cell surface associated-1.

(25.9\%) were T4 gastric cancer types, 4 cases $(7.4 \%)$ were T3, 3 cases $(5.6 \%)$ were $\mathrm{T} 1$ and 3 cases $(5.6 \%)$ were T2. A statistically significant difference was identified between the different $\mathrm{T}$ groups $(\mathrm{P}=0.039)$. Of the 22 patients with lymph node involvement data, 19 patients presented with lymph node involvement, with a statistically significant difference between the lymph node involvement groups $(\mathrm{P}=0.034)$. In the 44 cases with data available on whether there were coexisting metastasis in other organs, 24 cases $(44.4 \%)$ were positive. Of the 24 patients with coexisting metastasis in other organs, 4 had bone metastases and 14 had ovarian metastases. The remaining metastases were cutaneous (1 case), orbital metastases ( 1 case), liver ( 1 case) and other organs ( 3 cases) (data not shown). The most common additional metastases were ovarian (25.9\%; data not shown). A total of 36 cases provided information on the initial TNM stage as follows: 2 cases $(3.7 \%)$ of stage I disease; 4 cases $(7.4 \%)$ of stage II; 6 cases $(11.1 \%)$ of stage III and 24 cases (44.4\%) of stage IV. Staging information was unavailable for 18 patients owing to unknown tumor size, lymph node status or both (Table I).

For pathological diagnoses, 37 cases $(68.5 \%)$ were identified with signet ring cell carcinoma (SIG), 12 cases (22.2\%) with poorly differentiated adenocarcinoma (PDA), 3 cases $(5.6 \%)$ with mucinous adenocarcinoma (MAC) and 1 case (1.9\%) with adenocarcinoma (AC) (Table I). The immunohistochemistry images from one patient from Renji Hospital diagnosed with PDA and partial SIG are presented in Fig. 1A and B. This gastric cancer tumor tissue was positive for CK7, CK20 and mucin 1, cell surface associated-1 and was positive for Ki-67 (Fig. 1C-F).

Clinicopathological characteristics of breast metastasis. Clinicopathological characteristics of the breast metastases are presented in Table II. These were the same aforementioned patients with gastric cancer, but the clinical presentation data for breast lesions were available only in 52 cases $(96.3 \%)$. The median age of the patients with breast metastasis diagnosis 
Table II. Clinicopathological characteristics of patients with breast metastases.

\begin{tabular}{|c|c|c|c|c|}
\hline Variables & Patients & $\%$ & Log rank-value & P-value \\
\hline \multicolumn{5}{|l|}{ Sex } \\
\hline Female & 53 & 98.1 & & \\
\hline Male & 1 & 1.9 & 2.203 & 0.138 \\
\hline \multicolumn{5}{|l|}{ Age, years } \\
\hline$<45$ & 29 & 53.7 & & \\
\hline$\geq 45$ & 25 & 46.3 & 10.867 & 0.001 \\
\hline Median & 43 & & & \\
\hline \multicolumn{5}{|l|}{ Clinical presentation } \\
\hline Nodule & 40 & 74.1 & & \\
\hline Inflammatory & 12 & 22.2 & & \\
\hline Unknown & 2 & 3.7 & 0.195 & 0.659 \\
\hline \multicolumn{5}{|l|}{ Localization } \\
\hline Bilateral & 13 & 24.1 & & \\
\hline Left & 26 & 48.1 & & \\
\hline Right & 15 & 27.8 & 4.367 & 0.113 \\
\hline \multicolumn{5}{|c|}{ Axillary lymph node involvement } \\
\hline Positive & 23 & 42.6 & & \\
\hline Negative & 21 & 38.9 & & \\
\hline Unknown & 10 & 18.5 & 0.626 & 0.429 \\
\hline \multicolumn{5}{|c|}{ Ultrasonography manifestation } \\
\hline Nodules & 19 & 35.2 & & \\
\hline Skin thickening & 4 & 7.4 & & \\
\hline Negative & 5 & 9.3 & & \\
\hline Unknown & 26 & 48.1 & 0.974 & 0.614 \\
\hline \multicolumn{5}{|c|}{$\begin{array}{l}\text { Time between occurrence of } \\
\text { gastric cancer and breast metastasis }\end{array}$} \\
\hline Heterochronia & 30 & 55.6 & & \\
\hline Concomitant & 24 & 44.4 & 0.235 & 0.628 \\
\hline \multicolumn{5}{|l|}{ Diagnostic method } \\
\hline Needle biopsy of breast & 32 & 59.3 & & \\
\hline Surgery of breast & 13 & 24.1 & & \\
\hline Unknown & 9 & 16.7 & 0.400 & 0.527 \\
\hline \multicolumn{5}{|l|}{ Histology } \\
\hline $\mathrm{AC}$ & 6 & 11.1 & & \\
\hline SIG & 42 & 77.8 & & \\
\hline PDA & 4 & 7.4 & & \\
\hline MAC & 1 & 1.9 & & \\
\hline Unknown & 1 & 1.9 & 58.014 & $<0.001$ \\
\hline \multicolumn{5}{|l|}{ Gastric surgery } \\
\hline Positive & 26 & 48.1 & & \\
\hline Negative & 19 & 35.2 & & \\
\hline Unknown & 9 & 16.7 & 0.003 & 0.959 \\
\hline \multicolumn{5}{|l|}{ Chemotherapy } \\
\hline Positive & 32 & 59.3 & & \\
\hline Negative & 6 & 11.1 & & \\
\hline Unknown & 16 & 29.6 & 1.117 & 0.290 \\
\hline
\end{tabular}

PDA, poorly differentiated adenocarcinoma; SIG, signet ring cell carcinoma; MAC, mucinous adenocarcinoma; AC, adenocarcinoma. 

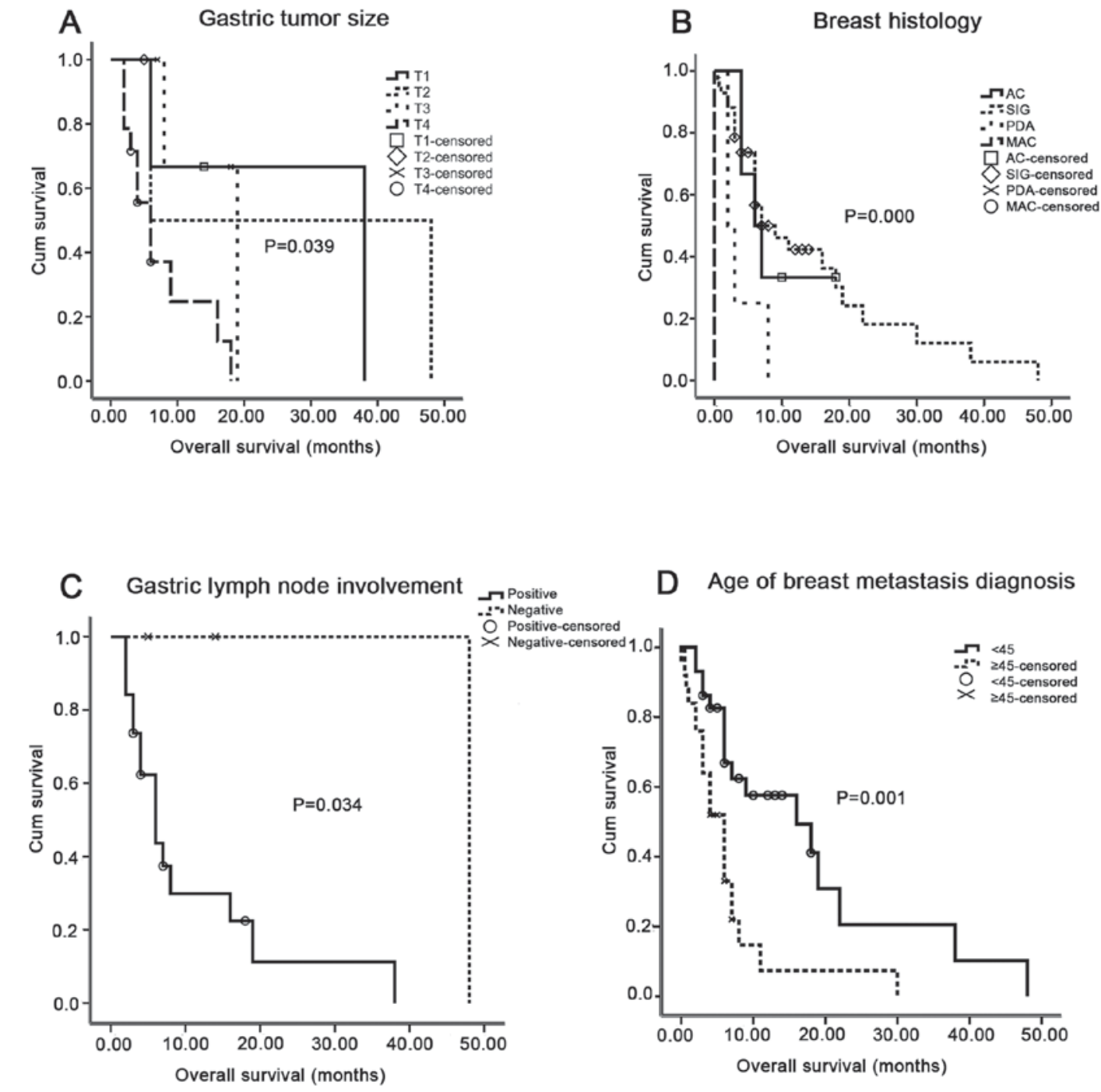

D Age of breast metastasis diagnosis

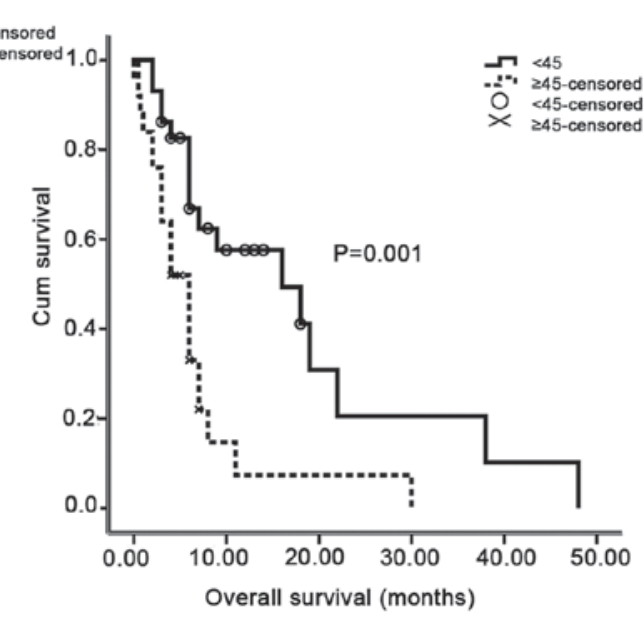

Figure 2. Association of OS time with clinic pathological factors, primary gastric tumor and breast metastasis characteristics. (A) Univariate analysis revealed that gastric tumor size was significantly associated with OS. Patients with a T4 stage tumor had the poorer survival time than those with T1-3 stage tumors. (B) Univariate analysis revealed that breast histology was significantly associated with OS. Patients with SIG had better survival time compared with patients with AC, PDA or MAC. (C) Univariate analysis revealed that gastric lymph node involvement was significantly associated with OS. Patients with gastric lymph node involvement had poorer survival time than those without involvement. (D) Univariate analysis revealed that the age at breast metastasis diagnosis was significantly associated with OS. Patients aged $<45$ years had better survival time than those aged $\geq 45$ years. OS, overall survival; AC, adenocarcinoma; SIG, signet ring cell carcinoma; PDA, poorly differentiated adenocarcinoma; MAC, mucinous adenocarcinoma.

was 43 years (range, 22-72 years). A significant difference was identified between the $<45$ and the $\geq 45$ year old age groups $(\mathrm{P}=0.001)$. Upon physical examination, palpable nodules and inflammatory changes in the breast were identified in 40 cases (74.1\%) and 12 cases (22.2\%), respectively. A total of 26 cases possessed lesions in the left breast $(48.1 \%), 15$ had lesions in the right breast $(27.8 \%)$ and 13 were bilateral $(24.1 \%)$. Axillary lymph node involvement data were available in 44 cases $(81.5 \%)$, 23 of which were positive for nodal involvement (42.6\%). Data from ultrasonic manifestation of breast metastasis were available for 28 cases $(51.9 \%$ ), with nodules (19 cases; 35.2\%) being the most common manifestation (Table II). However, there was no significant difference identified for any of these factors.

The median interval between primary diagnosis and metastatic presentation was 1.25 months (range, 0-72 months). Breast metastasis and gastric cancer were diagnosed simultaneously in 24 cases $(44.4 \%)$. Needle biopsy was performed for breast metastasis diagnosis in 32 cases (59.3\%) and surgery was performed in 13 cases $(24.1 \%)$. For breast histological diagnosis, 42 cases $(77.8 \%)$ were identified as SIG, 6 cases (11.1\%) as AC, 4 cases (7.4\%) as PDA and 1 case $(1.9 \%)$ as MAC, with a significant difference identified between these groups $(\mathrm{P}<0.001)$. (Table II) Notably, 10 cases differed in their pathology between the primary gastric cancer and breast metastasis.

Estrogen receptor (ER) expression data were available in 28 cases, progesterone receptor (PR) in 25 cases, human epidermal growth factor receptor-2 (Her-2) in 15 cases and GCDFP15 in 11 cases; all cases presented negative results. The result of one patient is presented in Fig. 1G-H. Three years later, this patient with metastatic breast cancer was diagnosed with primary gastric cancer and was positive for CEA and villin, and negative for mammaglobin (Fig. 1I-L).

Information on surgical treatment was available for 45 cases, of which 26 (48.1\%) received gastric surgery, whilst 
Table III. Multivariate analysis of prognostic factors for overall survival time in patients with breast metastases.

\begin{tabular}{lccc}
\hline Variables & P-value & HR & 95\% CI \\
\hline Age at breast metastasis diagnosis & 0.009 & 1.061 & $1.015-1.110$ \\
Gastric histology & 0.351 & 1.561 & $0.613-3.978$ \\
Breast histology & 0.045 & 3.662 & $1.029-13.036$ \\
Clinical presentation & 0.819 & 1.129 & $0.398-3.208$ \\
Localization of breast metastasis & 0.043 & 2.200 & $1.025-4.723$ \\
Axillary lymph node involvement & 0.617 & 0.779 & $0.293-2.071$ \\
Time to occurrence of the breast metastasis & 0.017 & 0.960 & $0.929-0.993$ \\
Gastric surgery & 0.051 & 3.283 & $0.996-10.823$ \\
\hline
\end{tabular}

P-values from multivariate analysis were calculated using Cox proportional hazards regression analysis. HR, hazard ratios; CI, confidence interval.
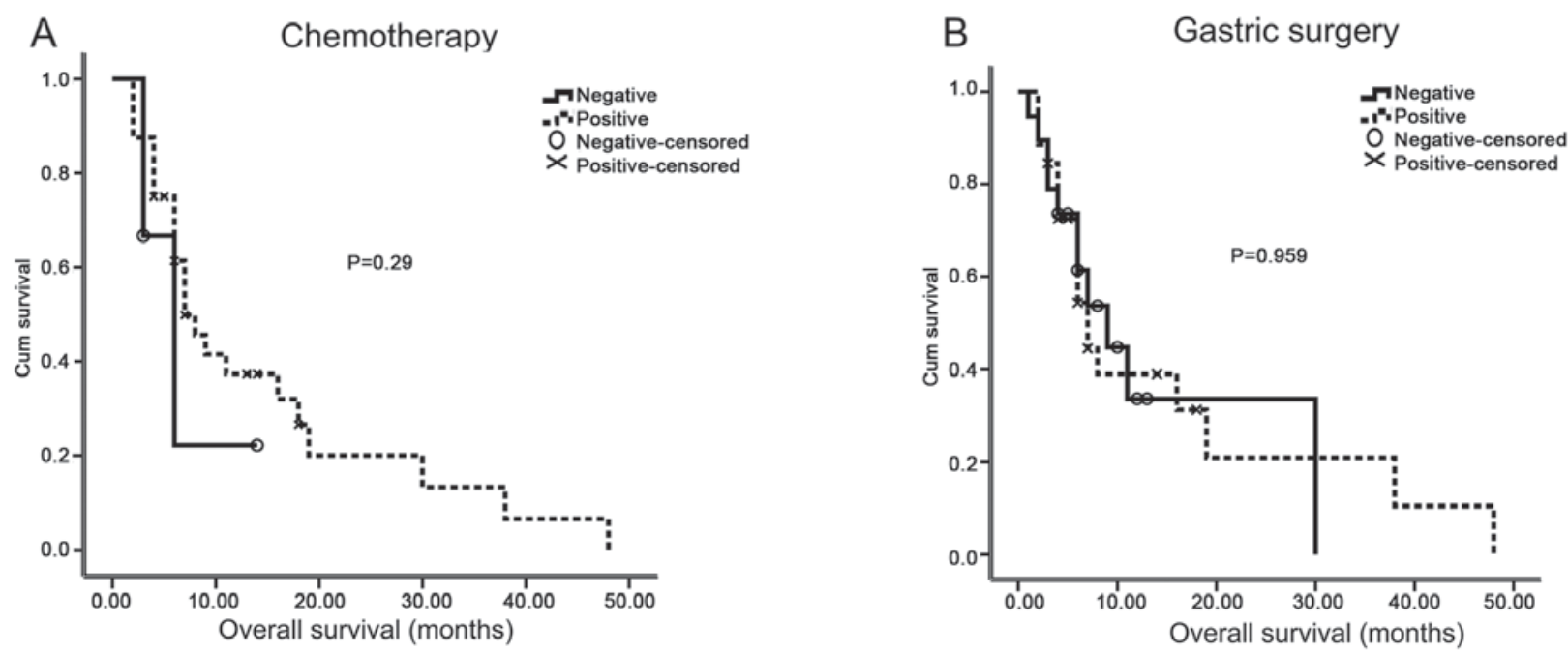

Figure 3. OS time in association with the type of therapy for patients with gastric cancer with breast metastasis. (A) Univariate analysis revealed that chemotherapy was unassociated with the OS of patients with breast metastasis. (B) Univariate analysis revealed that gastric surgery was unassociated with the OS of patients with breast metastasis. OS, overall survival.

the other $19(35.2 \%)$ did not. A total of 32 cases received chemotherapy $(59.3 \%), 6$ cases did not, and 16 cases provided incomplete data (Table II).

Survival. Data were available for 54 patients. The median survival time was 8.6 months (range, $0-48$ months). Univariate analysis of the association among OS time, clinicopathological factors, primary gastric tumor and breast metastasis characteristics was performed, and gastric tumor size, gastric lymph node involvement, age at breast metastasis diagnosis and breast histology were all significantly associated with OS time $(\mathrm{P}=0.039,0.034,0.001$ and $<0.001$, respectively; Fig. 2). However, survival analysis revealed that sex, Borrmann's classification, co-existing metastases in other organs, initial stage, tumor position and primary gastric cancer histology were not associated with OS time $(\mathrm{P}=0.138,0.381,0.764$, $0.238,0.052$ and 0.895 , respectively; Table I). At first, the association between the number of breast metastases and the OS time was analyzed using univariate analysis, and a significant association was identified $(\mathrm{P}<0.05)(69)$. Clinical presentation, localization of the breast metastasis, axillary lymph node involvement, ultrasonography performance, diagnostic method and time from occurrence of breast metastasis were also not associated with OS time $(\mathrm{P}=0.659$, $0.113,0.429,0.614,0.527$ and 0.628, respectively; Table II). In addition, gastric surgery and chemotherapy were not associated with breast metastasis patient overall survival ( $\mathrm{P}=0.959$, 0.290, respectively; Table II; Fig. 3). From further multivariate analysis, the time to occurrence $(\mathrm{P}=0.017)$, age $(\mathrm{P}=0.009)$, histology $(\mathrm{P}=0.045)$ and breast metastasis localization $(\mathrm{P}=0.043)$ were significant independent OS time indicators (Table III).

\section{Discussion}

The estimated rate of occurrence of non-primary breast malignancy reported in literature varies from $0.5-1.3 \%$ in clinical observation to $1.7-6.6 \%$ in autopsy series $(70,71)$. In the present study, all but one of the patients were female, and their median age was 43 years. In previous reports, the median age at diagnosis of patients with gastric cancer with breast metastasis was 46 years (9), and for patients with primary breast cancer was 
61 years in the USA and 56.99 years in Japan $(72,73)$. Breast metastases originating from gastric carcinoma tend to occur at younger ages than primary breast carcinomas (9). In the present study, the age was defined as the age at the diagnosis of breast metastasis. In univariate and multivariate analyses, patients aged $<45$ years had longer survival times than those $\geq 45$ years $(\mathrm{P}=0.001$ and $\mathrm{P}=0.009$, respectively). Thus, an age at diagnosis of breast metastasis of $<45$ years appears to be a positive prognostic factor. Breast metastasis from gastric cancer is rare, and the mechanism is not yet clear. The present study analyzed the results of current clinical observations. In one previous study, the majority of patients were at a higher stage (above AJCC stage III) and Borrmann IV type (4). In the present study, stage IV and Borrmann III types were the most common. In univariate analysis, patients with $\mathrm{T} 4$ or those with gastric lymph node involvement presented with the poorest cumulative survival rates of all patients $(\mathrm{P}<0.05)$, as these gastric cancer types are usually invasive. However, insufficient data were available for gastric tumor size and lymph node involvement; thus, these factors were not included in the multivariate analysis.

Breast metastasis symptoms are unspecific in terms of breast nodules, swelling, tenderness and pain compared with the symptoms of primary breast cancer (10). In the present study, nodules $(74.1 \%)$ were a more common clinical symptom than inflammation (22.2\%), and axillary lymph node involvement was also common. Ultrasound results including skin thickening and breast nodules, indistinguishable from those of primary breast cancer, were unassociated with OS time $(\mathrm{P}>0.05)$; thus, it suggests that it is difficult to diagnose metastatic breast cancer by clinical presentation or diagnostic imaging. Breast metastases were most common on the left side, consistent with the results of a previous study (13). This laterality may indicate the potential presence of another lymphatic pathway or preponderance to the breast from other organs including the left supraclavicular lymph node metastasis from gastric carcinoma. In multivariate analysis, breast metastasis localization was a significant prognostic factor of OS time ( $\mathrm{P}=0.043)$.

Biopsy and surgery on the breast masses were generally performed for diagnosis. Needle biopsies of the breast, including core needle biopsy or fine needle aspiration, may differentiate between primary and metastatic breast tumor types $(74,75)$. In the present study, a needle biopsy was used for $59.3 \%$ of the patients, providing a quick and accurate diagnosis, thus avoiding an unnecessary mastectomy. Immunohistochemistry was the primary method for identifying the tumor origin $(32,34)$. Of all the patients in a previous study, $\sim 77.8 \%$ presented with breast SIG, and $68.5 \%$ of patients presented with gastric SIG, which accounted for $\sim 10 \%$ of the gastric cases (11). In previous studies, SIG of the stomach was often observed in younger women (aged $<40$ years), and SIG of the primary breast was rare $(43,44,48,68)$. Differing histology of breast metastases was associated with $\mathrm{OS}$ time in univariate $(\mathrm{P}<0.001)$ and multivariate analyses $(\mathrm{P}=0.045)$ in the present study. In one reported case, immunohistochemical staining for breast metastasis from gastric cancer was negative for ER, PR, erb-B2 receptor tyrosine kinase 2 and GCDFP15 but positive for CEA, CK7 and CK20 (24). This phenomenon was also observed in the present study. It was identified that that breast tumors were metastatic from gastric carcinoma using immunohistochemistry. However, chemokines or chemokine receptors associated with breast metastases in gastric carcinoma were not identified in the present study; this should be investigated further.

In the metastatic process, mammary involvement may either be the first step or there may be a polymetastatic context (63). In the present study, $44.4 \%$ of patients suffered from concurrent metastasis at the time of breast metastasis, and $44.4 \%$ of patients presented with gastric cancer and synchronous breast metastases. The median interval between diagnosis of the primary disease and identification of the metastatic lesion was only 1.25 months. This result indicated that gastric carcinoma with breast metastasis progresses rapidly and that the potential of metastasis from gastric carcinoma is high, even in patients with no history of gastric cancer. The time to occurrence of breast metastasis was a significant independent OS time indicator in the multivariate analysis $(\mathrm{P}=0.017)$. In the present study, the overall prognosis of patients with breast metastasis from gastric carcinoma was generally poor; the median survival time was only 8.6 months. For clinical treatment, careful attention is required, particularly when a breast lesion is the first manifestation of an unknown primary malignancy. Unexpectedly, surgical intervention and chemotherapy were not associated with the survival of patients with breast metastases in the present study. However, previous advances in the development of anticancer agents, including trastuzumab and apatinib, have improved the prognosis of patients with unresectable advanced or recurrent gastric cancer $(1,24)$. Although there are no current clinical case reports to confirm this, to the best of our knowledge, these novel drugs may be effective in treating this rare disease.

A number of limitations should be noted regarding the retrospective design and long time span of the present study. Furthermore, with a few exceptions, certain information concerning the primary tumor and prognosis was unavailable, despite this being a large study concerning this disease. Nevertheless, the present study may shed light on the different factors that contribute to the improved survival rates of patients with this disease and provide impetus for future research on gastric cancer with breast metastasis.

\section{Acknowledgements}

The authors would like to thank the following investigators for supporting this article by providing information on their studies: Dr Fengchun Zhang, Department of Oncology, Suzhou Kowloon Hospital, Shanghai Jiaotong University School of Medicine (Suzhou, China); Dr Qiang Liu, Department of Pathology, Renji Hospital, School of Medicine, Shanghai Jiaotong University.

\section{Funding}

The present study was supported by the National Natural Science Foundation of China (grant no. 81301858) and the Suzhou Science and Technology Project (grant nos. SYS201404 and SYS201508).

\section{Availability of data and materials}

All data generated or analyzed during this study are included in this published article. 


\section{Authors' contributions}

All authors read and approved the final manuscript. YX, YM and WL participated in selecting cases and the writing of the manuscript. HW designed and supervised the project. YX and JL collected the clinical details of the patients and carried out statistical analysis.

\section{Ethics approval and consent to participate}

The present study was approved by the Ethics Committee of the Renji Hospital Affiliated to Shanghai Jiaotong University and written informed consent was obtained from all patients.

\section{Patient consent for publication}

All patients signed written informed consent for the publication.

\section{Competing interests}

The authors declare that they have no competing interests.

\section{References}

1. Siegel RL, Miller KD and Jemal A: Cancer statistics, 2015. CA Cancer J Clin 65: 5-29, 2015.

2. Lee SK, Kim WW, Kim SH, Hur SM, Kim S, Choi JH, Cho EY, Han SY, Hahn BK, Choe JH, et al: Characteristics of metastasis in the breast from extramammary malignancies. J Surg Oncol 101: 137-140, 2010.

3. Domanski HA and Mas-Morillas A: Breast metastases from pancreatic and ovarian carcinoma. Diagn Cytopathol 21: 154-155, 1999.

4. Gupta S, Gupta MK, Gupta R and Mishra RS: Breast metastasis of cervical carcinoma diagnosed by fine needle aspiration cytology. A case report. Acta Cytol 42: 959-962, 1998.

5. Heggarty P, McCusker G and Clements WD: Bilateral breast metastases from a renal carcinoma. Int J Clin Pract 52: 443-444, 1998.

6. Kayikçioğlu F, Boran N, Ayhan A and Güler N: Inflammatory breast metastases of ovarian cancer: A case report. Gynecol Oncol 83: 613-616, 2001.

7. Adamovich TL and Simmons RM: Ductal carcinoma in situ with microinvasion. Am J Surg 186: 112-116, 2003.

8. Torre LA, Bray F, Siegel RL, Ferlay J, Lortet-Tieulent J and Jemal A: Global cancer statistics, 2012. CA Cancer J Clin 65: 87-108, 2015.

9. Iesato A, Oba T, Ono M, Hanamura T, Watanabe T, Ito T, Kanai T, Maeno K, Ishizaka K, Kitabatake H, et al: Breast metastases of gastric signet-ring cell carcinoma: A report of two cases and review of the literature. Onco Targets Therapy 8: 91-97, 2015

10. Kwak JY, Kim EK and Oh KK: Radiologic findings of metastatic signet ring cell carcinoma to the breast from stomach. Yonsei Med J 41: 669-672, 2000.

11. Otsuji E, Yamaguchi T, Sawai K and Takahashi T: Characterization of signet ring cell carcinoma of the stomach. J Surg Oncol 67: 216-220, 1998 .

12. Hasegawa S, Yoshikawa T, Yoshida T, Osaragi T, Cho H, Tsuburaya A, Kobayashi O and Sairenji M: A case of breast metastasis of gastric cancer. Gan to Kagaku Ryoho 34: 1115-1118, 2007 (In Japanese).

13. Parrell Soler C, Palacios Marqués A, Saco López L, Bermejo De Las Heras R and Pertusa Martínez S: Breast metastatic localization of signet-ring cell gastric carcinoma. ISRN Obstet Gynecol 2011: 426150, 2011.

14. Christophorou MA, Ringshausen I, Finch AJ, Swigart LB and Evan GI: The pathological response to DNA damage does not contribute to p53-mediated tumour suppression. Nature 443: 214-217, 2006.

15. Matsuoka S, Ballif BA, Smogorzewska A, McDonald ER III, Hurov KE, Luo J, Bakalarski CE, Zhao Z, Solimini N, Lerenthal Y, et al: ATM and ATR substrate analysis reveals extensive protein networks responsive to DNA damage. Science 316: 1160-1166, 2007.
16. Chan N, Koritzinsky M, Zhao H, Bindra R, Glazer PM, Powell S, Belmaaza A, Wouters B and Bristow RG: Chronic hypoxia decreases synthesis of homologous recombination proteins to offset chemoresistance and radioresistance. Cancer Res 68: 605-614, 2008.

17. Sobhian B, Shao G, Lilli DR, Culhane AC, Moreau LA, Xia B, Livingston DM and Greenberg RA: RAP80 targets BRCA1 to specific ubiquitin structures at DNA damage sites. Science 316: 1198-1202, 2007.

18. Akcay MN: Metastatic disease in the breast. Breast 11: 526-528, 2002.

19. Quinn JE, Kennedy RD, Mullan PB, Gilmore PM, Carty M, Johnston PG and Harkin DP: BRCA1 functions as a differential modulator of chemotherapy-induced apoptosis. Cancer Res 63: 6221-6228, 2003.

20. Wei J, Costa C, Ding Y, Zou Z, Yu L, Sanchez JJ, Qian X, Chen H, Gimenez-Capitan A, Meng F, et al: mRNA expression of BRCA1, PIAS1, and PIAS4 and survival after second-line docetaxel in advanced gastric cancer. J Natl Cancer Inst 103: 1552-1556, 2011.

21. Yamaguchi H, Kitayama J, Ishigami H, Emoto S, Yamashita $\mathrm{H}$ and Watanabe T: A phase 2 trial of intravenous and intraperitoneal paclitaxel combined with S-1 for treatment of gastric cancer with macroscopic peritoneal metastasis. Cancer 119: 3354-3358, 2013.

22. Peng YF, Imano M, Itoh T, Satoh T, Chiba Y, Imamoto $H$, Tsubaki M, Nishida S, Yasuda T and Furukawa H: A phase II trial of perioperative chemotherapy involving a single intraperitoneal administration of paclitaxel followed by sequential S-1 plus intravenous paclitaxel for serosa-positive gastric cancer. J Surg Oncol 111: 1041-1046, 2015.

23. Zhu CP and Tang SH: Gastric cancer with breast metastasis in young patient: A case report. Guangdong Med J: 2760, 2013 (In Chinese).

24. He CL, Chen P, Xia BL, Xiao Q and Cai FL: Breast metastasis of gastric signet-ring cell carcinoma: A case report and literature review. World J Surg Oncol 13: 120, 2015.

25. Briest S, Horn LC, Haupt R, Schneider JP, Schneider U and Höckel M: Metastasizing signet ring cell carcinoma of the stomach-mimicking bilateral inflammatory breast cancer. Gynecol Oncol 74: 491-494, 1999.

26. Luk YS, Ka SY, Lo SS, Chu CY and Ma MW: An unusual case of gastric cancer presenting with breast metastasis with pleomorphic microcalcifications. J Breast Cancer 15: 356-358, 2012.

27. Madan AK, Ternovits C, Huber SA, Pei LA and Jaffe BM: Gastrointestinal metastasis to the breast. Surgery 132: 889-893, 2002.

28. Sato T, Muto I, Fushiki M, Hasegawa M, Hasegawa M, Sakai T and Sekiya M: Metastatic breast cancer from gastric and ovarian cancer, mimicking inflammatory breast cancer: Report of two cases. Breast Cancer 15: 315-320, 2008.

29. Qin R and Ma XG: A case report of metastatic signet ring cell carcinoma to the breast from stomach. Acta Acad Med Militaris Tertiae: 2170-2170, 2005 (In Chinese).

30. Ren XQ: Gastric cancer with bilateral orbital, double breasts and multiple bone metastasis: A case report. Chin Commun Doctors 13: 296, 2011.

31. Lin RY, Yang YM and Chen HY: 1 case of bilateral breast and axillary lymph node metastasis after gastric cancer surgery. Canc Res Prev Treat 4: 218, 1990 (In Chinese).

32. Weng HY, Zhang B, Lin YL and Hong M: Bilateral breast metastasis of gastric cancer: A case report. Hainan Med J 22: 132, 2011.

33. Qi H, Yu XT and Kong FH: Gastric adenocarcinoma with mammary glands metastasis: A case report. J China Tradit Chin Med Inform 04: 398-399, 2012.

34. Tang F, Jiang GY and Wang NX: Gastric cancer with breast metastasis: A case report and literature review. Chin J Breast Dis (electronic version) 6: 707-712,2012 (In Chinese).

35. Hong YZ and Gao XY: Gastric cancer with breast metastasis: A case report. Chin J Gen Surg 22: 127, 2013.

36. Wang ZC, Wu B and Li J: Metastatic gastric cancer to the breast: A case report. Chin J Gen Surg 20: 939, 2011.

37. Wang M, Zhao X and Wu WX: Gastric carcinoma with breast metastasis: A case report. Chin J Clin Oncol: 5, 2007.

38. Ye CM, Xue MX, Chen B, Huang ZM and Zeng FH: A gastric cancer patient with breast metastasis. Chin J Gen Surg: 569, 2007.

39. Zhu JD and Fang JX: Breast metastasis from gastric cancer: A case report. Chin J Prac Surg: 113, 1994.

40. Li DF, Liang XL, Qi QH and Jiang QM: Gastric cancer with breast recurrence: A case report. J Qilu Oncol: 374, 2001. 
41. Wei XH: Gastric cancer with breast metastasis: A rare case report. Inner Mongolia Med J: 436, 2004.

42. Yang LF: A case of breast metastasis after 4 years of gastric cancer surgery. J Clin Surg: 17, 2011 (In Chinese).

43. Yang J, Li A and Zhao XH: A case report of poorly differentiated adenocarcinoma of stomach with male breast metastasis. J Rare Uncommon Dis: 50-51, 2001.

44. Shi L, Zhao W, Chen P, Wang H, Fang X and He CL:Metastatic tumor to breast from primary gastric carcinoma: A case report. Chin J Gen Surg: 357, 2016.

45. Zheng YJ, Deng YC, Hua C, Liu YB and Li ZD: A case of breast metastasis after gastric cancer surgery. Chin J Pract Surg: 51, 2005

46. Tang Y, Chen W and Wang Y: Ultrasonographic manifestation of breast cancer metastasis of gastric cancer: A case report. Chin J Ultrasound Med: 343, 2009 (In Chinese).

47. Schmutzer KJ, Zaki AE and Regan JF: Gastric carcinoma in a 22-year-old Negro woman with metastases to ovaries and breast. A case report. J Natl Med Assoc 65: 426-428 passim, 1973.

48. Boutis AL, Andreadis C, Patakiouta F and Mouratidou D: Gastric signet-ring adenocarcinoma presenting with breast metastasis World J Gastroenterol 12: 2958-2961, 2006.

49. Sandison AT: Metastatic tumours in the breast. Br J Surg 47: 54-58, 1959.

50. Nance FC, MacVaugh H III and Fitts WT Jr: Metastatic tumor to the breast simulating bilateral primary inflammatory carcinoma. Am J Surg 112: 932-935, 1966.

51. Togo S and Kasumi F: A case of gastric cancer metastatic to the breast. Gan no rinsho: 386-393, 1980 (In Japanese).

52. Nielsen M, Andersen JA, Henriksen FW, Kristensen PB, Lorentzen M, Ravn V, Schiødt T, Thorborg JV and Ornvold K: Metastases to the breast from extramammary carcinomas. Acta Pathol Microbiol Scand A 89: 251-256, 1981.

53. Kasuga Y, Senga O, Hanamura N, Iida F, Oota H, Katsuyama T and Tsuchiya S: A case of bilateral metastatic breast carcinoma from gastric carcinoma. Gan No Rinsho Jpn J Cancer Clin 32: 407-412, 1986 (In Japanese)

54. Tachibana S, Asano M, Miya K, Hino T, Furuichi $\mathrm{N}$ and Misawa K: A case report of gastric cancer with breast metastasis. J Clin Surg 41: 1719-1722, 1986.

55. Alexander HR, Turnbull AD and Rosen PP: Isolated breast metastases from gastrointestinal carcinomas: Report of two cases. J Surg Oncol 42: 264-266, 1989.

56. Hamby LS, McGrath PC, Cibull ML and Schwartz RW: Gastric carcinoma metastatic to the breast. J Surg Oncol 48: 117-121, 1991.

57. Mishina Y, Ohtsuka K, Yamamura H, Kanai T, Kitagawa Y, Kawai M and Koyama Y: A case or metastasis of gastric cancer to the mammary gland. Nihon Rinsho Geka Gakkai Zasshi (J Jpn Surg Assoc) 54: 112-117, 1993.

58. Cavazzini G, Colpani F, Cantore M, Aitini E, Rabbi C, Taffurelli M, Pari F, Bellomi A, Bertuzzi A and Smerierl F: Breast metastasis from gastric signet ring cell carcinoma, mimicking inflammatory carcinoma. A case report. Tumori 79: 450-453, 1993

59. Kudo H, Sakatani T, Shibata S, Ishiguro M, Nishidoi H and Murakami S: A case of gastric cancer metastasized to the breasts J Jpn Surg Assoc 60: 1486-1489, 1999 (In Japanese).

60. Di Cosimo S, Ferretti G, Fazio N, Mandalà M, Curigliano G, Bosari S, Intra M, Latronico A. Goldhirsch A: Breast and ovarian metastatic localization of signet-ring cell gastric carcinoma. Ann Oncol 14: 803-804, 2003.

61. Qureshi SS, Shrikhande SV, Tanuja S and Shukla PJ: Breast metastases of gastric signet ring cell carcinoma: A differential diagnosis with primary breast signet ring cell carcinoma. J Postgrad Med 51: 125-127, 2005.
62. Isobe T, Yokoyama G, Fujii T, Kawamura D, Nakagawa S and Shirouzu K: A case of breast metastasis of gastric cancer progressed rapidly. Nihon Rinsho Geka Gakkai Zasshi (J Jpn Surg Assoc) 67: 2800-2804, 2006.

63. Krichen Makni S, Abbes K, Khanfir A, Frikha M and Sellami Boudawara T: Metastatic signet ring cell carcinoma to the breast from stomach. Cancer Radiotherapie: J De La Soc Francaise De Radiother Oncol 11: 276-279, 2007 (In French).

64. Gugić D, Josipa F, Šambić P, Mrčela M and Romić S: Breast metastases from gastric carcinoma-a case report. Libri Oncologici 35: 59-62, 2007.

65. Timuçin Ç, Abdullah A, Semir P and Abdurrahman I: Gastric ring cell carcinoma metastasis to the breast: Two case reports. Turk J Cancer 39: 62-65, 2009.

66. Avgerinou G, Flessas I, Hatziolou E, Zografos G, Nitsios I, Zagouri F, Katsambas A and Kanitakis J: Cutaneous metastasis of signet-ring gastric adenocarcinoma to the breast with unusual clinicopathological features. Anticancer Res 31: 2373-2378, 2011.

67. Kajitani T: The general rules for the gastric cancer study in surgery and pathology. Part I. Clinical classification. Jpn J Surg 11: 127-139, 1981.

68. Marano L, Boccardi V, Braccio B, Esposito G, Grassia M, Petrillo M, Pezzella M, Porfidia R, Reda G, Romano A, et al: Comparison of the 6 and 7th editions of the AJCC/UICC TNM staging system for gastric cancer focusing on the ' $\mathrm{N}$ ' parameter-related survival: The monoinstitutional NodUs Italian study. World J Surg Oncol 13: 215, 2015.

69. Diab SG, Elledge RM and Clark GM: Tumor characteristics and clinical outcome of elderly women with breast cancer. J Natl Cancer Inst 92: 550-556, 2000.

70. Bohman LG, Bassett LW, Gold RH and Voet R: Breast metastases from extramammary malignancies. Radiology 144: 309-312, 1982.

71. Hajdu SI and Urban JA: Cancers metastatic to the breast. Cancer 29: 1691-1696, 1972.

72. Verdial FC, Etzioni R, Duggan C and Anderson BO: Demographic changes in breast cancer incidence, stage at diagnosis and age associated with population-based mammographic screening. J Surg Oncol 115: 517-522, 2017.

73. Kinoshita T, Fukui N, Anan K, Iwamoto T, Niikura N, Kawai M, Hayashi N, Tsugawa K, Aogi K, Ishida T, et al: Comprehensive prognostic report of the Japanese Breast Cancer Society Registry in 2004. Breast Cancer 23: 39-49, 2016.

74. Kobayashi G and Cobb C: A case of amelanotic spindle-cell melanoma presenting as metastases to breast and axillary lymph node: Diagnosis by FNA cytology. Diagn Cytopathol 22: 246-249, 2000.

75. Deshpande AH, Munshi MM, Lele VR and Bobhate SK: Aspiration cytology of extramammary tumors metastatic to the breast. Diagn Cytopathol 21: 319-323, 1999.

This work is licensed under a Creative Commons Attribution-NonCommercial-NoDerivatives 4.0 International (CC BY-NC-ND 4.0) License. 